\section{Stigma by association}

\section{Psychological factors in relatives of people with mental illness}

MARGARETA ÖSTMAN and LARS KJELLIN
Negative attitudes exist in society towards people with mental illness. Discrimination occurs across every aspect of social and economic existence. Research has documented stigmatisation and its negative consequences for people with mental illnesses (Farina, 1982; Link et al, 1987).

Stigma is defined as a sign of disgrace or discredit that sets a person apart from others. Goffman (1963), a sociological researcher with an interest in psychiatric stigma, defined stigma in terms of undesirable 'deeply discrediting' attributes that 'disqualify one from full social acceptance' and motivate efforts by the stigmatised individual to hide the mark when possible. However, he also commented that the difference between a normal and a stigmatised person was a question of perspective, not reality, and that stigma is in the eye of the beholder. A more recent definition has been proposed by Link \& Phelan (2001) in which stigma exists when elements of labelling, stereotyping, separating, status loss and discrimination co-occur in a power situation that allows these processes to unfold. the relatives had at times thought that the patient would be better off dead, and 10\% had experienced suicidal thoughts. Stigma by association was greater in relatives experiencing mental health problems of their own, and was unaffected by patient background characteristics.

Conclusions Interventions are needed to reduce the negative effects of psychological factors related to stigma by association in relatives of people with mental illness.

Declaration of interest The study was supported by grants from the Vardal Foundation, Sweden (V200I 14I). et al, 1998; Byrne, 2001; Struening et al, 2001).

To widen the knowledge of stigma by association in families of patients with severe mental illness it might be valuable to measure aspects of psychological distress and psychological burden perceived by members of these families. Accordingly, understanding how the situation of stigma affects family members both in connection with psychological feelings towards the ill person and in connection with psychiatric services can increase the knowledge of the situation of these families. Different aspects of family burden and participation in care are important parts of a Swedish study of the quality of mental health services during the period 1997-1999. In this study relatives of both compulsorily and voluntarily admitted patients were interviewed about different aspects of their burden, the need for support and their participation in the care of the patient. In particular, the psychological effects of being a relative of a person with severe mental illness were assessed.

The aim of the part of the study reported here was to investigate factors of psychological significance related to stigma by association in the relatives. Further aims are to investigate differences in these factors according to background variables concerning both the patient and the relative, and the relationship between the relative's mental health and perceived associative stigma.

\section{METHOD}

\section{Study design}

The research reported here is part of an international study on the use of coercion in Scandinavian mental health care systems. This Swedish multi-centre study focuses on voluntary and compulsory psychiatric in-patient care.

A consecutive sample of committed patients and a random sample of patients voluntarily admitted to acute psychiatric wards were included in the study. People aged under 18 years and over 70 years, people with a main diagnosis of alcohol or substance misuse, severe learning difficulties or severe dementia, mentally disordered offenders, and individuals not speaking Swedish were excluded. The remaining patients were contacted by a psychiatrist within 5 days of their admission and invited to participate in 
the study. A psychiatrist assessed the patients' psychosocial functioning and psychopathology, and assigned a diagnosis according to DSM-IV criteria (American Psychiatric Association, 1994). Three weeks after admission to hospital a clinical psychologist or a psychiatrist interviewed the patients and asked their permission to interview a close relative, nominated by the patient.

Relatives were identified as spouses, parents, children or 'other' (mainly siblings), or as non-relatives. The interview with the relative was performed about a month after the patient's admission to hospital, by a trained psychiatric social worker. None of the interviewers was involved in the treatment of the patient. Some information concerning the patient was collected from case notes and an interview with the patient. The study was approved by the research ethics committee of the Medical Faculty of the University of Uppsala.

\section{Setting}

The study has as its subject the in-patient psychiatric services of four different Swedish centres, each with comprehensive responsibility for a geographically defined catchment area comprising both urban and rural areas, and with a total population of 90000-260000 inhabitants. The psychiatric departments in the counties had 3.13-5.13 beds per 10000 inhabitants for short-term psychiatric care.

\section{Participants}

A consecutive sample of 196 committed patients and a random sample of 179 voluntarily admitted patients were asked to take part. At the first interview 138 committed and 144 voluntarily admitted patients participated, and at the follow-up interview (around 3 weeks after admission) 118 and 117 patients, respectively, took part. At the second interview the patients were asked for permission to contact a relative. Altogether 162 relatives -73 relatives of the committed patients and 89 relatives of the voluntarily admitted patients - were interviewed. Drop-out occurred at two different stages in the investigation: when patients refused contact with a relative or stated that they lacked a relative to interview, and when the relative refused an interview or when contact failed. Dropout occurred twice as often at the first stage. Of the relatives asked to participate,
$13 \%$ refused or were unable to perform the interview.

Patients whose close relatives were interviewed did not differ from the entire sample in terms of gender, age, diagnosis and level of functioning. Thirty-eight per cent of the patients were men. The mean age was 43 years (range 19-69 years). Thirty-one per cent of both the committed and the voluntarily admitted patients had a psychosis diagnosis according to DSMIV, including schizophrenia, delusional disorders, schizoaffective and schizophreniform disorders and atypical psychoses; $44 \%$ had a diagnosis of affective mood disorder and $25 \%$ had other diagnoses. Their psychosocial function was measured using the Global Assessment Scale (American Psychiatric Association, 1987); the mean score was 37 (range 10-71). Background characteristics of the participating relatives are shown in Table 1.

\section{Interview with the relatives}

The instrument used was a semi-structured questionnaire, asking relatives about their situation as the relative of a person with severe mental illness and their experiences in relation to both compulsory and voluntary psychiatric care. The questionnaire was developed from clinical experience and focuses on the burden of relatives, their need for support, and participation in the care. It contains 95 questions, measuring the relative's own objective feelings. The instrument includes eight dimensions of burden and participation in care, as well as measures of family attitudes towards mental health care in a general hospital. The instrument takes 60-90 min to administer, of which the 'burden' items take about $45 \mathrm{~min}$. The time frame for the question is in most cases the month before the patient's admission to hospital. The instrument was developed for face-to-face interviews, but is also suitable for use over the telephone. The interrater reliability has been calculated and found satisfactory, with Cohen's $\kappa=0.98$ and an absolute correspondence of ratings in $96 \%$ of the questions. The test-retest reliability concerning burden and participation in care has been found to be generally satisfactory, measured both as a percentage of concordance and as Cohen's $\kappa$ (Östman \& Hansson, $2000 a$ ). The instrument is also available in an English version and has been further described by Schene et al (1994).

The following items describing psychological factors related to associated stigma were investigated, and the respondents' answers were classified as yes/no:

(a) Do you find the staff of the psychiatric services to be supportive in carrying the burden of being a relative of a person with severe mental illness?

Table I Background characteristics of the relatives participating in the study

\begin{tabular}{|c|c|c|c|}
\hline & Men $(n=78)(\%)$ & Women $(n=84)(\%)$ & Total $(n=162)(\%)$ \\
\hline \multicolumn{4}{|l|}{ Age (years) } \\
\hline 19 & 5 & 0 & 3 \\
\hline $20-39$ & 32 & 23 & 27 \\
\hline $40-59$ & 43 & 51 & 48 \\
\hline $60+$ & 20 & 26 & 23 \\
\hline \multicolumn{4}{|l|}{ Relationship to the patient } \\
\hline Spouse & $47^{1 * * *}$ & 12 & 29 \\
\hline Parent & 10 & $42^{2 * * *}$ & 27 \\
\hline Son/daughter & 16 & 18 & 13 \\
\hline Other, sibling & 21 & 33 & 27 \\
\hline Non-relative & 6 & 2 & 4 \\
\hline Living in the same household & $51^{3 * *}$ & 25 & 38 \\
\hline \multicolumn{4}{|l|}{ Duration of relationship (years) } \\
\hline $0-19$ & 27 & 14 & 20 \\
\hline $20-39$ & 62 & 69 & 66 \\
\hline $40-59$ & II & 17 & 14 \\
\hline
\end{tabular}

I. $\chi^{2}=36.9 ;$ d.f. $=4, P<0.001$.

2. $\chi^{2}=34.7 ;$ d.f. $=4, P<0.001$

3. $\chi^{2}=$ II.9; d.f. $=I, P<0.01$.

$* * P<0.01, * * * P<0.001$. 
(b) Do you feel inferior to the staff of the psychiatric services in conversations?

(c) Has the person's mental illness affected the possibilities of your having company of your own?

(d) Do you feel supported by anyone in carrying the burden of having a relative with mental illness?

(e) Has the person's mental illness impaired the relationship between you and that person?

(f) Are there times when you wish that the person with mental illness had never been born, or that you and the person had never met?

(g) Has the person's mental illness led to any mental health problems of your own?

(h) Is the burden of the situation of being a relative so heavy that you have thought of suicide?

(i) Are there times when you think that the ill person would be better off dead?

\section{Statistical analysis}

The chi-squared test was used to test for differences in proportions. Comparisons of answers to items describing psychological factors between subgroups were carried out with non-parametric tests, the KruskalWallis test and the Mann-Whitney $U$-test. A $P$ level of 0.05 was considered significant.

\section{RESULTS}

\section{Relationship between assessed psychological factors and background characteristics of the participants}

Eighty-three per cent of the relatives experienced a burden in one or more of the assessed psychological factors of stigma by association.

When psychological factors related to stigma assessed in this study were compared with the patients' diagnosis (Table 2) only one difference was found. Relatives of patients with an affective disorder were less likely to believe that the patient would be better off dead $(9 \% v .24 \%$ and $27 \%$; $\chi^{2}=7.8$, d.f. $=2, P=0.020$ ). No other difference was found in relation to diagnosis. No significant differences were found due to the patient's age, gender or global assessment score, or whether the patient's admission was compulsory or voluntary.
When controlling for background variables of the relatives, there was no difference among the measured factors of stigma in relation to the relative's age. Depending on the relative's gender there was a difference in one respect: a greater proportion of women had thought that the ill relative would be better off dead ( $72 \% v .28 \% ; \chi^{2}=6.1$, d.f. $=2, P=0.048$ ).

When the nature of the relationship was considered (Table 3), some differences were found: spouses were more often negatively affected in their possibilities of having company of their own $(55 \%$ v. 21$33 \% ; \chi^{2}=12.5$, d.f. $\left.=3, P=0.006\right)$, and more often had times of wishing that the patient had never been born or that the relative and the patient had never met $\left(32 \% \quad\right.$ v. $\quad 5-23 \% ; \quad \chi^{2}=8.2, \quad$ d.f. $=3$, $P=0.043)$. Spouses also more seldom believed that the ill relative would be better off dead $\left(4 \% \quad v .21-33 \% ; \chi^{2}=10.3\right.$, d.f. $=3, P=0.016)$.

When the relative lived with the patient, a greater proportion reported that the patient's mental illness had affected their possibilities of having company of their own $\left(51 \% v .24 \% ; \chi^{2}=12.4\right.$, d.f. $=1$, $P<0.001)$. Furthermore, there was a smaller proportion who sometimes believed that the patient would be better off dead $(3 \% v$. $27 \%$; $\chi^{2}=14.2$, d.f. $\left.=1, P<0.001\right)$ and a greater proportion of relatives who sometimes wished that the patient had never been born or that the relative and the patient had never met $(30 \%$ v. $16 \%$; $\chi^{2}=4.3$, d.f. $=1, P=0.038$ ).

\section{Psychological factors of stigma related to relatives' own mental health problems}

Among the relatives who felt that the patient's mental illness had caused mental health problems in themselves $40 \%$ of the total group of relatives - a greater proportion sometimes believed that the ill person would be better off dead $\left(26 \% v .12 \% ; \chi^{2}=5.03\right.$, d.f. $\left.=0.025\right)$. This group was also more likely to have had suicidal thoughts $\left(20 \%\right.$ v. $3 \% ; \chi^{2}=12.5$, d.f. $=1, P<0.001$ ).

\section{DISCUSSION}

Despite increasing awareness and discussion of stigma by association or family stigma, empirical researchers in mental health care have paid little attention to the topic compared with the broader topic of family burden. When relatives of people with severe mental illness are interviewed about their situation there is no easy delimitation between the topics of family burden, concerning subjective psychological burdens, and family stigma. However, assessing different aspects of associated stigma, measured both as family members' perceptions of treatment by others, and as psychological reactions to the situation of being related to a person with severe mental illness, may shed further light on the topic.

\section{Psychological factors related to stigma}

The results showed that a relatively high proportion of relatives considered that the patient's mental illness had affected the possibilities of having company of their own or had influenced relations with others, and had also led to mental health problems in the relatives themselves. A striking finding was that, for one group of relatives, these circumstances had seriously affected their thoughts about life and death, both in connection with their ill relative and in terms of suicidal thoughts of their own. Additionally, these relatives believed that the ill relative would be better off dead, and/or wished that the patient and the relative had never met and that the patient had never been born.

A majority of the relatives obtained support in carrying the burden of being related to a person with severe mental illness, mostly from other family members or their network of close friends, and more seldom from employees of the psychiatric services. Relatives' feelings of inferiority to staff in conversation, which is a stigmatising experience, may be an explanation for the low levels of cooperation between relatives and professionals.

\section{Patient background factors}

Minimal differences were found between psychological factors related to stigma among relatives and the background characteristics of the patient, whether age, gender, form of diagnosis or psychosocial functioning. This may illustrate that the situation of being a close relative of a person with severe mental illness is in itself a factor of importance, and contradicts the conventional wisdom of anti-stigma initiatives, that members of the public differentiate between illnesses. Furthermore, our results indicate differences in psychological 


\begin{tabular}{|c|c|c|c|c|}
\hline & \multicolumn{3}{|c|}{ Patient diagnosis } & \multirow{2}{*}{$\begin{array}{c}\text { Total } \\
(n=162) \\
(\%)\end{array}$} \\
\hline & $\begin{array}{l}\text { Psychosis } \\
(n=50)(\%)\end{array}$ & $\begin{array}{l}\text { Affective disorder } \\
\qquad(n=7 \mathrm{I})(\%)\end{array}$ & $\begin{array}{l}\text { Other diagnosis } \\
\qquad(n=4 I)(\%)\end{array}$ & \\
\hline $\begin{array}{l}\text { The staff of the psychiatric services were supportive in carrying the burden of being } \\
\text { a relative of a person with severe mental illness }\end{array}$ & 18 & 22 & 32 & 24 \\
\hline The relative felt inferior to the staff of the psychiatric services in conversations & 20 & 32 & 32 & 28 \\
\hline $\begin{array}{l}\text { The patient's mental illness had affected the relative's possibilities of having company } \\
\text { of his/her own }\end{array}$ & 35 & 35 & 27 & 34 \\
\hline $\begin{array}{l}\text { The relative had support from someone in carrying the burden of being a relative } \\
\text { of a person with mental illness }\end{array}$ & 70 & 66 & 59 & 65 \\
\hline $\begin{array}{l}\text { The patient's mental illness had impaired the relationship between the relative and } \\
\text { the patient }\end{array}$ & 24 & 30 & 17 & 25 \\
\hline $\begin{array}{l}\text { There were times when the relative wished that the patient had never been born or } \\
\text { that the relative and the patient had never met }\end{array}$ & 22 & 21 & 20 & 21 \\
\hline The patient's mental illness had led to mental health problems in the relative & 40 & 44 & 34 & 40 \\
\hline The burden on the relative was so heavy that the relative had had suicidal thoughts & 6 & II & 12 & 10 \\
\hline The relative sometimes believed that the ill person would be better off dead & 24 & 9* & 27 & 18 \\
\hline
\end{tabular}

Chi-squared test: $* P<0.05$.

factors of stigma according to the relative's gender and relationship to the patient. Female relatives were more prone to believe that the patient would be better off dead, and spouses (of whom a majority were men) were more affected in their possibilities of having company of their own and more often had times wishing that the relative and the patient had never met. In contrast to other relatives, spouses almost never believed that the patient would be better off dead. Our results may indicate, as seen in an earlier study by Noh $\&$ Avison (1988), specific gender differences among relatives in coping with their burdensome situation.

\section{Relationship between stigma by association and the relatives' mental health}

The findings of a high level of occurrence of psychological distress among relatives of people with severe mental illness are in accordance with earlier studies of relatives

Table 3 Differences in psychological factors related to stigma in subgroups of relatives

\begin{tabular}{cccc}
\multicolumn{3}{c}{ Subgroup } \\
\hline $\begin{array}{c}\text { Spouses } \\
(n=47)\end{array}$ & Parents & Grown-up children & Others, mostly \\
$(n=43)$ & $(n=2 I)$ & siblings $(n=5 I)$
\end{tabular}

(\%)

(\%)

The staff of the psychiatric services were supportive in carrying the burden of being

30

28

24

a relative of a person with severe mental illness

The relative felt inferior to the staff of the psychiatric services in conversations

\begin{tabular}{lrrr}
21 & 26 & 43 & 29 \\
$55^{* *}$ & 33 & 29 & 21 \\
68 & 72 & 76 & 58 \\
32 & 14 & 38 & 21 \\
$32 *$ & 14 & 5 & \\
& & & 23 \\
49 & 47 & 43 & 28 \\
13 & 16 & 5 & 5 \\
$4 *$ & 21 & 33 & 23 \\
\hline
\end{tabular}

The patient's mental illness had affected the relative's possibilities of having company of his/her own

The relative had support from someone in carrying the burden of being a relative of a person with mental illness

The patient's mental illness had impaired the relationship between the relative and the patient

There were times when the relative wished that the patient had never been born or that the relative and the patient had never met

The patient's mental illness had led to mental health problems in the relative The burden on the relative was so heavy that the relative had had suicidal thoughts The relative sometimes believed that the ill person would be better off dead

Kruskal-Wallis test: $* P<0.05 ; * * P<0.01$. 
where the patient had been admitted to hospital (Scottish Schizophrenia Research Group, 1987, 1988). An earlier study by Östman \& Hansson (2000b) reported a relationship between the relative's mental health and family burden, as well as participation in care and the relative's own need for support. In all areas, relatives who had no mental health problems seemed to live a life more of their own, were more satisfied with the patient's treatment and more often had a positive view of the quality of the psychiatric services. These earlier findings agree reasonably well with our findings of more psychological factors of stigma when the relatives experience mental health problems themselves. That relatives with their own mental health problems more often think that the patient would be better off dead and have more suicidal thoughts of their own ought to lead to new efforts to decrease the psychological costs in these families. Furthermore, a wellfunctioning and supportive network around a person with mental illness has been shown to reduce relapse (Bebbington $\&$ Kuipers, 1994; Cornwall \& Scott, 1996).

\section{Limitations of the study}

Although the study has limitations in its use of a semi-structured interview with single questions for assessment of different factors of burden and of psychological distress, it also has the strength of investigating themes not previously approached. The semi-structured interview method makes it possible to obtain information and assess topics of a psychological nature, questions of life and death, and factors related to associated stigma, in a research design with a relatively large sample size.

\section{REFERENCES}

American Psychiatric Association (1987) Diagnostic and Statistical Manual of Mental Disorders (3rd edn, revised) (DSM-III-R). Washington, DC: APA

(1994) Diagnostic and Statistical Manual of Mental Disorders (4th edn) (DSM-IV). Washington, DC: APA

Bebbington, P. \& Kuipers, L. (1994) The predictive utility of expressed emotion in schizophrenia: an aggregate analysis. Psychological Medicine, 24, 707-718.

Byrne, P. (200I) Psychiatric stigma. British Journal of Psychiatry, 178, 28I-284.

Cornwall, P. \& Scott, J. (1996) Burden of care psychological distress and satisfaction with services in the relatives of acutely mentally disordered adults. Social Psychiatry and Psychiatric Epidemiology, 3I, 345-348.

Farina, A. (1982) The stigma of mental disorders. In In The Eye of the Beholder (ed. A. Miller), pp. 305-363. New York: Praeger.

\section{CLINICAL IMPLICATIONS}

- Stigma by association in relatives of people with mental illness is itself a cause of psychological distress, and this is more pronounced when relatives themselves experience mental health problems.

- There are minimal gender differences in coping with the burdensome situation of having a relative with severe mental illness, although women tend to express more inner thoughts of death.

- For some people, having a relative with severe mental illness leads to serious thoughts about life and death, both in connection to the ill person and in terms of suicidal thoughts.

\section{LIMITATIONS}

- Almost a third of eligible relatives were not interviewed, because either the patient refused contact with relatives or the relative refused to participate.

- The use of a semi-structured interview with single questions for assessment of different factors of burden and of psychological distress may limit comparisons with other results.

Owing to the exclusion criteria the results cannot be generalised to relatives of all people with mental illness.

MARGARETA ÖSTMAN, Dr Med Sc, Division of Psychiatry, University of Lund; LARS KJELLIN, Dr Med Sc Psychiatric Research Centre, Örebro, Sweden

Correspondence: Dr Margareta Östman, Department of Clinical Neuroscience, Division of Psychiatry, University Hospital SE-22I 85 Lund, Sweden. Tel: 46 173849; fax: 46 173884;

e-mail: margareta.ostman@psykiatr.lu.se

(First received 24 April 2002, final revision I August 2002, accepted I August 2002)

Goffman, E. (1963) Stigma: Notes on the Management of Spoiled Identity. Englewood Cliffs, NJ: Prentice-Hall.

Lefley, H. (1987) Impact of mental illness in families of mental health professionals. Journal of Nervous and Mental Disease, 175, 613-619.

Link, B. \& Phelan, J. (200I) Conceptualizing stigma Annual Review of Sociology, 27, 363-385.

_, Cullen, F., Frank, J., et al (1987) The social rejection of ex-mental patients: understanding why labels matter. American Journal of Sociology, 92 , $|46|-1500$.

Mehta, S. \& Farina, A. (1988) Associative stigma: perceptions of the difficulties of college-aged children of stigmatized fathers. Journal of Social Clinical Psychology, 7 192-202.

Noh, S. \& Avison, W. (1988) Spouses of discharged psychiatric patients: factors associated with their experience of burden. Journal of Marriage and Family, $\mathbf{5 0}$ 377-389.

Östman, M. \& Hansson, L. (2000a) Family burden and care participation. A test-retest reliability study of an interview instrument concerning families with a severely mentally ill family member. Nordic Journal of Psychiatry, 54, 327-332.
_ $\&$ _ (2000b) Family burden, participation in care and mental health - an II-year comparison of the situation of relatives to compulsorily and voluntarily admitted patients. International Journal of Social Psychiatry, 46, 191-200.

Phelan, J., Bromet, E. \& Link, B. (1998) Psychiatric illness and family stigma. Schizophrenia Bulletin, 24 II5-126.

Schene, A., Tessler, R. \& Gamache, G. (1994) Instruments measuring family or caregiver burden in severe mental illness. Social Psychiatry and Psychiatric Epidemiology, 29, 228-240.

Scottish Schizophrenia Research Group (1987) The Scottish First Episode Schizophrenia Study. IV. Psychiatric and social impact on relatives. British Journal of Psychiatry, I50, 340-344.

— (1988) The Scottish First Episode Schizophrenia Study. V. One-year follow-up. British Journal of Psychiatry, I52, 470-476.

Struening, E., Perlick, D., Link, B., et al (200I) The extent to which caregivers believe most people devalue consumers and their families. Psychiatric Services, 52 , 1633-1638. 